Relmecs, junio 2017, vol. 7, no. 1, e022, ISSN 1853-7863

Universidad Nacional de La Plata. Facultad de Humanidades y Ciencias de la Educación. Centro Interdisciplinario de Metodología de las Ciencias Sociales.

Red Latinoamericana de Metodología de las Ciencias Sociales

\title{
No me discuta. Migración reciente en Argentina y medios de comunicación desde el análisis sociológico-lingüístico del discurso
}

\author{
Don't argue with me. Recent migration and media in Argentina \\ from sociological-linguistic discourse analysis
}

\author{
Ernesto Meccia (*) \\ * Universidad de Buenos Aires - Universidad Nacional del Litoral, Argentina |
}

\section{PALABRAS CLAVE}

Migración reciente

Massmediatización

Formación discursiva

Análisis sociológico-lingüístico del discurso

Subjetividades discursivas

Intercambios polémicos

\section{KEYWORDS}

Recent Migration

Massmediatization

Discursive Formation

Scientific research

Sociological and Linguistic

Discourse Analysis

Discursive Subjectivities

Controversial Exchanges

\section{RESUMEN}

Inspirados en la noción de formación discursiva de Michel Foucault, se realiza una aproximación a la massmediatización de la migración reciente en Argentina (2016) aplicando el método del análisis sociológico-lingüístico del discurso, especialmente inspirados en la propuesta de Irene Vasilachis de Gialdino. Por consiguiente, a los fines de la elaboración de una reflexión sociológica, se destacan los recursos lingüísticos utilizados en los intercambios para comprender la idea de sociedad y migración que tienen los hablantes. Lejos del armado de algún cotejo entre discurso y realidad se procura hacer visibles las reglas o las rejillas de especificación a través de las cuales la formación discursiva hacer ver y hace hablar sobre la migración, dotándose así de su propio objeto. Se presta especial atención a la clase de subjetividad que esta formación imagina y reclama a sus enunciatarios.

\section{Recibido: 16 de febrero de 2017 | Aceptado: 2 de mayo de 2017 | Publicado: 14 de junio de 2017}




\section{Presentación}

Sobre fines de 2015, en Argentina, asumió la titularidad del poder ejecutivo Mauricio Macri, en representación de una alianza entre el partido político que lidera (Unión-PRO) y la Unión Cívica Radical (alianza llamada Cambiemos) y del 51.34 \% del voto popular. De inmediato, por todos los medios de comunicación -remarco en especial la televisión- se comenzó a hablar de política, estado y sociedad de un modo hondamente fundacionalista. Los gobiernos anteriores que -según los detractores- habían implementado políticas populistas llevando al pueblo a vivir por encima de sus posibilidades y a pretender lo impretendible, habían dejado un país devastado, una "pesada herencia" en múltiples planos de la organización social, de la cual había que librarse. Pero este paso liberador podría darse si la sociedad entera se entregaba sin concesiones a un proceso cognitivo-moral de "sinceramiento" (sic), metáfora que dentro de la cosmovisión de Cambiemos suponía aceptar una seria e impostergable exhortación para ver las cosas en su medida real. Acorde a las ideologías neoliberales (re)comenzaron a circular nociones que referían a un estado inflamado, sobrecargado de funciones y de personas, sobredemandado económicamente e ineficiente; en suma, un estado incapaz de funcionar como debería si no se le quitaba la "grasa" (sic) que lo cubría, es decir, distintas excedencias sociales que entorpecían el desenvolvimiento normal de sus mecanismos.

Formaron parte de esta excedencia un conjunto de programas de intervención social, sus respectivos empleados, las cargas impositivas de determinados sectores de la economía, las condicionalidades referidas al comercio exterior, una aerolínea de bandera, etcétera. Cada uno de estos ejemplos de excedencia tuvo su momento de cobertura mediática, cobertura incomparable, sin embargo, a la que tuvo la inmigración latinoamericana y no-europea, visto el violento repentismo y la carga moral depositada. En efecto, atreverse a "sincerar" los debates sobre la inmigración dejando a un lado la "hipocresía" (sic) y lo "políticamente correcto" (sic) apareció como un requisito moral (ser sincero) para tomar una lección (cognitiva, por definición) en pos de observar los efectos deletéreos que produciría un estado excedido de garantismo y para saber cómo barajar las cartas y darlas de nuevo. Observar la inmigración, siguiendo los vericuetos de los discursos que se escucharon entre octubre y noviembre de 2016, contenía una doble promesa: saber cómo serían “ellos” pero también cómo seríamos "nosotros” en un proclamado contexto de decadencia; programa nada desdeñable para los habitantes de un país donde la primacía del significante "cambio” propuesta por el gobierno dependía de una insistente construcción discursiva de imágenes contrastantes del pasado, esto es, del tiempo en que "nosotros” (los integrantes de la categoría enunciataria imaginada) no habríamos hecho las cosas bien.

Desde un punto de vista sociológico resulta interesante notar cómo, también, en el tratamiento mediático de este fenómeno puede apreciarse la dinámica alternante entre el ideario latente y el ideario manifiesto de una sociedad. Una de las figuras más combatidas por los discursos antiinmigratorios es la del ciudadano de pensamiento "políticamente correcto" (sic). En uso, esta expresión -también denigrada por el pensamiento "progresista"- se refiere a un conjunto de modales tolerantes del ciudadano común respecto de cuestiones urticantes que forman parte del panorama cotidiano. Por ejemplo, modales tolerantes (o neutros) respecto de la diversidad sexual, de las libres elecciones, del aborto, del derecho a la protesta social, del derecho al trabajo, etcétera; muchos de los cuales han encontrado formas extendidas de no-beligerancia y/o de cortesía en los intercambios lingüísticos. Aunque "insincera" -ya que se tolera lo que en verdad no se aprueba- esa actitud tiene, sin embargo, cierta positividad social. Queremos decir, que se diga en voz alta algo insincero de efectos neutros (lo manifiesto) significa que algo sincero pero de efectos sociales negativos ha sido puesto en estado de latencia. Y ello, desde cierta perspectiva es un logro: la censura generalizada hacia la manifestación desembozada de censuras respecto de los derechos de los demás debiera tenerse en cuenta como el precario resultado -pero resultado al fin- de la operatividad de ciertas fuerzas que habitan el entramado discursivo; fuerzas que tuvieron la capacidad de poner debajo de la alfombra -claro que relativamente- los costados 
menos civilizatorios de la sociedad.

Lejos de ello, los discursos antiinmigratorios o, mejor decir, la mayoría de los discursos políticos que se escuchan y leen desde diciembre de 2015 y que tienen como megapremisa moral el compromiso del sinceramiento, operan al revés. Parecieran provenir de una matriz discursiva que los emparenta peligrosamente en una inquietante función sistemática: la de levantar la alfombra y llevar a la dimensión manifiesta lo que estaba en estado de relativa latencia. Nos encontramos así con enunciadores no solamente desbocados en lo que respecta a sus opiniones personales sino con exhortadores seriales a que se desprecie y se abandone lo "políticamente correcto" (sic), acción-actitud que equivaldría a entrar en la antesala de la verdad de lo que seríamos y de lo que debiéramos hacer como sociedad. Si bien referida originalmente a la economía, la metáfora del "sinceramiento" (sic) proferida por los medios de comunicación y numerosos referentes de la alianza de gobierno se reconoce en el mismo sentido en muchos otros niveles: no tapar más lo que ocurre, en el convencimiento que el discurso destapador traería a la luz la verdad inapelable de las cosas, esas cosas que el "relato" (sic) había tapado y/o tergiversado. En este horizonte, el discurso antiinmigratorio asomó como el ejemplo paradigmático.

En este artículo aplicaremos el método del análisis sociológico-lingüístico del discurso (Vasilachis de Gialdino, 2007, 2013 y 2016) sobre tres programas de la televisión que tocaron el tema inmigratorio reciente. El primero de ellos PPT (Periodismo para todos) conducido por Jorge Lanata (edición del 16/10/16) ${ }^{1}$ presentó un informe sobre los extranjeros en tanto usuarios de la Universidad de Buenos Aires y del sistema de salud pública del Gran Buenos Aires. Fue una emisión de alto impacto. Del segundo de ellos, llamado La mirada y conducido por Roberto García (edición del 31/10/16)ํㅡㄹ , tomaremos las declaraciones del senador nacional Miguel Ángel Pichetto, asimismo muy comentadas por los medios en los días sucesivos. Y por último, analizaremos la edición del 02/11/16 del programa Intratables conducido por Santiago del Moro ${ }^{3}$, programa de amplia audiencia y novedoso formato, en el que gran parte del informe se armó en base a las declaraciones del mencionado senador.

Aplicar el método del análisis sociológico-lingüístico del discurso supone instrumentalizar en todo momento, a los fines de un análisis sociológico, algunos de los saberes de las disciplinas lingüísticas. Para Irene Vasilachis de Gialdino, este método:

observa el vínculo entre discurso y sociedad ubicándose en el segundo de los términos de la conjunción y privilegiando el punto de vista de la sociología, es decir, el de los aportes epistemológicos, metodológicos y teóricos de esa disciplina. Esa es, pues, su perspectiva especial, la que no debe confundirse con la de la sociolingüística que para Kress (2004: 443), entre otros, remite a la covariación de las formas sintácticas y textuales con la variación de los rasgos de los contextos sociales en los cuales el lenguaje es utilizado. (Vasilachis de Gialdino, 2007, p. 152) ${ }^{4}$

En tanto que análisis sociológico y lingüístico que pretende construir una reflexión sociológica partiendo del lenguaje, es cierto que interesará identificar los recursos lingüísticos utilizados por los hablantes (a modo ejemplificativo, los géneros de los discursos, así como su contexto, coherencia, estrategias, presupuestos, los roles semánticos, el dialogismo tripartito entre el enunciador, el enunciatario y el tercero ausente, los deícticos, las implicaturas, los tropos y los topos argumentales, así como los tipos de intercambios polémicos a través de los cuales los hablantes pretenden ganar verosimilitud). Sin embargo, en ningún caso el interés es propiamente lingüístico. A considerable distancia y buscando el beneficio de las prácticas interdisciplinarias, en el escrito buscaremos constantemente observar los recursos lingüísticos movilizados, porque se asume que a través de ellos los enunciadores buscan fijar su posición acerca de cómo debiera ser una sociedad, de cómo debiera funcionar, con quiénes tendría que hacerlo, con cuántos. En suma: observando el habla podrían 
encontrarse valiosos indicios acerca de cuáles son los "modelos interpretativos" (Vasilachis de Gialdino, 2007) de la realidad que emplean a diario los sujetos.

De esta forma, aspiramos a demostrar que, de la inabarcable cantidad de recursos que podrían movilizarse cuando se habla sobre cualquier tema, los enunciadores seleccionan solamente algunos, lo cual, a su vez, indicaría que toda selección lingüística "está incrustada en un orden moral que opera práctica y profundamente en la vida social.” (Jayyusi, 1984, p. 2 en Vasilachis de Gialdino, 2007, p. 157).

Los modelos interpretativos de la realidad social, por lo general, no son pensamientos que aparezcan en forma explícita en los discursos, de allí que se haga necesario observar el empleo de recursos lingüísticos y estrategias argumentativas para representar el escenario de la realidad social. Para Irene Vasilachis de Gialdino, esos modelos suponen:

a) alguna forma de ser de la sociedad y de la organización social; b) uno o varios modos de diferenciación o jerarquización entre sus miembros; c) un tipo de relaciones sociales predominante y, por tanto y d) una mayor o menor posibilidad de los actores sociales individuales o colectivos, por un lado, de contribuir a la construcción de la sociedad, de sus valores, de sus normas, de sus significados, de sus orientaciones y, por el otro, de proponer y obtener una transformación en los sistemas de distribución de bienes tanto materiales cuanto simbólicos, espirituales y de trascendencia. (Vasilachis de Gialdino, 2007, p. 153)

Con las formas del lenguaje, entonces, los sujetos fabricarían representaciones, pero no de la realidad que los circunda, sino antes que nada de las concepciones que tienen de la sociedad y de los lugares que ocupan sus miembros (ellos mismos, en primer lugar); concepciones, desde luego, cargadas de presuposiciones valorativas y normativas tantas veces infalsables, como veremos. Dicho con una sola expresión: si existe algo que un discurso representa es una idea de "orden social”.

He aquí uno de los sentidos de referirse al antirepresentacionismo en los análisis sociológico-lingüísticos del discurso que encuentra en Michel Foucault (2008) un antecedente ineludible. Si los discursos fueran mera representación de la realidad lo que se tendría serían conjuntos de signos que, con más o menos fortuna, reenviarían a enunciadores y enunciatarios a un referente acabado que "se preexistiría a sí mismo" (Foucault, 2008, p. 72). Para Foucault, ese no es el caso: los discursos están formados por signos que hacen mucho más que "indicar", "describir" o "revelar" cosas, los discursos son, en realidad, prácticas discursivas que “forman” "sistemáticamente aquellos objetos de los que hablan.” (2008, p. 81). Consecuentemente, el programa analítico corre hacia afuera de la lengua y hacia adentro de la historia y la sociedad:

sustituye el tesoro enigmático “de las cosas” previas al discurso, por la formación regular de objetos que sólo en él se dibujan. [El desaf ío es] definir esos objetos sin referencia al fondo de las cosas, sino refiriéndolos al conjunto de reglas que permiten formarlos como objetos de un discurso y constituyen así sus condiciones de aparición histórica. (Foucault, 2008, pp. 78-79)

Entonces, escribir desde el método del análisis sociológico-lingüístico del discurso sobre migrantes recientes en Argentina, en 2016, exige vincular el esfuerzo de la reflexión con la puesta en evidencia de las reglas por medio de las cuales nuevamente se habla de ellos, con hacer visibles las nuevas "rejillas de especificación" (Foucault, 2008, p. 68) del fenómeno que, sin duda, son propuestas cognoscitivas (o grillas interpretativas) realizadas desde el ideario político hegemónico que se escenifica en los medios de comunicación. Un ideario político que -valga la aclaración- no es una invención ni una propiedad exclusiva de la alianza de gobierno. Es más, en varias oportunidades, pareciera que son los mismos periodistas y comunicadores quienes “apuran” al gobierno con el temario discursivo del (re)ordenamiento social. Sea como sea, lo cierto es que desde diciembre de 2015, quien encienda la televisión será testigo de una innegable instanciación de una 
matriz discursiva preexistente en el imaginario social.

Por consiguiente, en lo que sigue, los discursos sobre la inmigración reciente serán abordados más como un objeto que se dio a sí mismo esta formación discursiva y menos como la "realidad" que esta formación dice que existe "afuera". Y si hay algo que dicho objeto representa son los ideales de sociedad sostenidos/vehiculizados por los enunciadores.

Como nota técnico-metodológica, declaramos que optamos por un análisis consecutivo de las tres emisiones televisivas. Podríamos haber hecho lo contrario: optar por una exposición conjuntista amontonando los elementos "eco" de las intervenciones. Sin embargo, creímos que esa decisión quitaría como dato discursivo justamente al "tiempo", importante aquí en varios sentidos. Primero, porque entre las emisiones (un lapso total de veinte días) se tramitaron alineamientos, discrepancias y realineamientos; segundo, porque dentro de cada emisión, además de darse lo mismo, se hace posible observar movidas microdiscursivas a medida que los intercambios polémicos avanzan (por ejemplo, entre dos periodistas en principio afines ideológicamente); tercero -lo cual, en verdad, es una conclusión- porque privilegiar el agrupamiento de los elementos "eco" en el contexto de un debate tan candente (en el cual -por ejemplo- los enunciadores, además de macular a los migrantes, cuidan su propia imagen), equivaldría a quitarle el pulso a lo dicho y no poca comprensión situacional a la dinámica interlocutiva. En fin, una cantidad de información valiosa que no convendría sacrificar en pos de una falsa sincronía que podría hacernos ver (tal vez demasiado) rápido una supuesta saturación semántica de contenidos.

\section{Argentina, País Generoso}

PPT" (Periodismo para todos) es un programa semanal que tiene una elevada audiencia y fuerte impacto en franjas de televidentes y sectores del periodismo contrarios a las políticas implementadas por los gobiernos kirchneristas. En muchas de sus emisiones se presentaron graves informes sobre corrupción, de repercusiones en los ámbitos judiciales. Si lo miramos teniendo en cuenta la noción de género discursivo, podría decirse que cumple bastante con los imperativos situacionales, las formas de organización de los contenidos y las marcas textuales propias del género "periodismo de investigación”, aunque debiera remarcarse una dirección -admitida y expuesta en voz alta por el mismo conductor- de sus investigaciones que tenían como misión reorganizar el voto de los televidentes en términos antikirchneristas. En lo que podemos considerar como otra manifestación de la metáfora del sinceramiento, el conductor optó por transparentar su discurso, destinándolo abiertamente a enunciatarios -contrarios a los gobiernos kirchneristas- que sabrían perdonarle, justamente en razón de su exuberante sinceridad, las infracciones al contrato del género de la investigación que, en la mayoría de los otros programas, se recubría con nociones de neutralidad o de subjetividad controlada.

Las emisiones se estructuran en bloques en los cuales el conductor o los co-conductores presentan los resultados de las investigaciones, con testimonios de afectados y, especialmente, voces expertas. En el caso que nos ocupa, dos coconductores oficiaban de investigadores, mientras que el restante coconductor y el conductor, la mayoría de las veces, realizaban intervenciones conectoras y de refuerzo entre las distintas ideas y hallazgos expuestos. Durante las exposiciones, un insistente didactismo pretendía fijar más aún los dichos. En la parte inferior de la pantalla -por ejemplo- aparecían volantas de atmósfera en las que podía leerse:

“Boom de extranjeros en la UBA.”

“Estudiantes extranjeros en la UBA ya son casi 13000 alumnos.” 
"País generoso. 360 millones para estudiantes extranjeros.”

Como demostrara Teun Van Dijk en sus investigaciones sobre la inmigración hacia Europa, comienza el “juego de los números” (2003), es decir, la aparición de los números absolutos sin indicar qué porcentaje representan (algo que, sin embargo, fugazmente habían dicho los periodistas). En la UBA esa cifra indica un porcentaje del $4.4 \%$. El didactismo aparecía debajo de la pantalla pero también cambiaba de tamaño hasta ocupar la pantalla entera: en efecto, los periodistas estaban respaldados por pantallas de gran tamaño con información que luego la cámara convertía en el único campo de visión:

"Presupuesto anual UBA: cada alumno \$28.400, total de extranjeros: \$ 360.000.000. Argentina, país generoso.”

"Enero 2015 - enero 2016: extranjeros en hospitales bonaerenses 340.000, prácticas médicas 592.000.”

"La mayoría de los extranjeros son paraguayos, brasileros, bolivianos, uruguayos.”

Vayamos a los intercambios hablados. El conductor inicia con una reflexión moral densa que marcará a fuego el resto del informe; una reflexión bastante extendida en otros programas y también a propósito de muchos otros temas:

JL.: A veces nos sentimos culpables en Argentina de que nos interese el país. ¿Es raro, no? Decimos: ¿no será demasiado nacionalista hablar de esto? Para nada. $\underline{5}$

MM: Para que te des una idea, estos son los últimos datos oficiales, tenés 13000 extranjeros en la Universidad de Buenos Aires

JL: ¿13000? ¡Guau!

MM: Son el 4.4 por ciento del total pero hace 20 años eran el 1.2 por ciento.

JL: O sea que más se triplicó, se cuadruplicó.

MM: Mirá, hay un cambio muy importante en las dos últimas décadas, desde los 90 hasta el año pasado con lo que está pasando en la UBA. Primero, hoy, la mayoría de los estudiantes de la UBA vienen de escuelas privadas. Y una minoría viene de escuelas públicas.

JL: De estudiantes argentinos de la UBA.

MM: Exactamente. Pero esto se da muy groseramente en los últimos años cuando de cien estudiantes que crece la matrícula en la UBA, ochenta vienen de escuelas privadas, cinco son extranjeros y solo 15 vienen de escuelas públicas. (...). Entonces el crecimiento de la matrícula en la UBA en los últimos diez, quince años tiene que ver con un boom de estudiantes que vienen de escuelas privadas con un boom de estudiantes que vienen del extranjero y con una minoría que viene de escuelas públicas argentinas.

La presentación del tema migratorio -en términos verbales y visuales- construye una idea demográfica de invasión y una idea moral de uso indebido de los fondos públicos, funcionando la segunda como legitimadora de la primera, cualquiera sea la cifra. De lo contrario no podría entenderse por qué se insiste en una cuadruplicación en veinte años que, transcurrido ese lapso, representa el $4.4 \%$ de la población de la entidad aludida. Que se construye esa imagen moral es innegable aún más cuando el juego de los números sigue su curso, aclarando que los migrantes comparten el usufructo de la universidad pública con los hijos de las clases acomodadas. 
Se sabe que en una formación discursiva convergen distintas fuerzas lingüísticas, de diversa procedencia, que en otros contextos pueden cumplir una función diferente. De aquí que hayamos dicho que las formaciones discursivas nunca terminan de instanciarse, como si la instanciación fuera el imperativo/desafío al que la enfrentan las circunstancias de una eterna actualidad. La instanciación, que es de varias formas impredecible y ad hoc, consiste en una actividad -no necesariamente concertada- de integrar, hoy, en lo dicho, elementos de sentido solidarios con los contornos dados al objeto que la formación va construyendo. En este caso, podemos observar cómo, a la vez que se instancian los prejuicios y la sospecha hacia los migrantes no-europeos, también el enunciador instancia, instrumentalizando el fenómeno inmigratorio, una histórica posición ideológica contraria a la gratuidad de la enseñanza en las universidades argentinas. Movidas complejas del lenguaje, el saber discursivo sabe encontrar las oportunidades para hacer ver y hacer valer su postura respecto del objeto actual (migrantes "usureros" del sistema educativo), no importa si movilizando otro objeto que se dio otra formación discursiva que operaba en otro campo social (hijos de clases medias "usureros" del mismo sistema). Si existe el parentesco exigido por la formación actual, es decir, si cumple con sus reglas de sinonimia moral, cualquier movilización cognitiva es legítima, ya que se la pondera como eficiente.

David Snow et al. (1986), sociólogos estudiosos de la dimensión cognitiva en la formación de los ciclos de protesta social, resaltaron una actividad que desarrollan los movimientos sociales en sus intentos de persuadir sobre la importancia de las causas que defienden. Llamaron framebridging a la estrategia discursiva y organizacional de poner en relación o de "tender un puente" entre grupos ideológicamente congruentes pero que hasta ese momento no estaban estructuralmente conectados. Estaban preocupados por el estudio de cómo los movimientos sociales pueden ensanchar sus bases sociales y mejorar la acción. Así, por ejemplo, se pueden tender puentes para conectar sistemáticamente distintos segmentos de desocupados presuntamente rivales (desocupados del sistema formal o informal), o de distintos afectados por la violencia de género (feministas con gays y lesbianas), o de distintos afectados por las consecuencias ambientales de la reprimarización de la economía (víctimas de la megaminería con desplazados por el cultivo de la soja). Si bien Snow et al. no la utilizaron directamente en el campo del análisis sociológico-lingüístico del discurso, nos pareció una categoría teórica pertinente, ya que el informe que estamos analizando arranca munido de la fuerza que le provee el puente que tiende entre dos categorías de "usufructuantes" de las alicaídas arcas públicas insospechados previamente de un parentesco. Es un punto de partida fuerte.

La presentación de los resultados de la investigación periodística retorna al juego de los números: presentará las estimaciones presupuestarias a través de un precario argumento de escalada ascendente, en el que no podemos dejar de notar que, en aproximadamente un minuto, se menciona cinco veces el sustantivo/adjetivo “extranjero" (sic), desestimando la capacidad de inferencia semántica de un enunciatario, sin embargo, tan definido:

MM: Yendo a los estudiantes extranjeros en la UBA y este es el dato muy impactante, que vamos a verlo en detalle, si uno toma el costo anual de lo que pagan todos los argentinos por financiar la Universidad de Buenos Aires por alumno, son 28.400 pesos por año que la sociedad aporta por estudiante. Teniendo en cuenta la cantidad de extranjeros, por ese grupo de casi 13000 extranjeros, el estado argentino está aportando más de $\mathbf{3 6 0}$ millones de pesos por año para que los estudiantes extranjeros estudien gratuitamente. Si uno hace el promedio de que estudien cinco, seis años para que terminen sus carreras, el estado argentino va a terminar aportando para que estos estudiantes extranjeros estudien gratuitamente en Argentina más de 2000, 2500 millones de pesos.

En este tramo, el discurso adopta un didactismo extremo que, por motivos ideológicos, necesita remarcar constantemente a "ellos" y a "nosotros", de allí que -como dijimos- no dé lugar a las implicaturas semánticas, entendidas éstas como las que pueden deducirse lógicamente de los enunciados ya proferidos. 
Vuélvase al fragmento y nótese la marcación obsesiva de la extranjería, que hace trizas el aserto "a buen entendedor, pocas palabras", como si el enunciador tuviera temor de que el estudiante pudiera eludir súbitamente su condición de "extranjero" (sic) y entonces quedarse sin un insumo clave para afianzar el objeto del que habla.

Eso sí: a falta de implicaturas semánticas aparecen potentes implicaturas pragmáticas, es decir: estados de cosas que lo van a afectar (a él y a los que son como él) y que el enunciatario puede inferir, no directamente de los enunciados literalmente proferidos, sino de los contextos comunicativos creados por los mismos. De hecho, lo que puede observarse es que todos los contenidos del fragmento (los actores, las cifras, los tiempos, las situaciones) se subordinan a un buscado efecto de hipérbole para persuadir acerca de que, de seguir así, no habría presupuesto universitario ni arca del estado que aguante. El estado de cosas que se busca dibujar es el de una superficie sobre la que se deposita mucho peso y que, llegado un momento, se quebrará. En otro momento, el informe -¿paradójicamente?- hacía referencia a la baja cantidad de egresados de la universidad pública comparados con los ingresados, es decir, que según el mismo enunciador era más que probable que los estudiantes extranjeros no estén en la universidad la cantidad de años que señaló para denunciar las cifras totales del presupuesto.

El efecto hipérbole dibuja, con tono admonitorio e inminente, un estado de las cosas que tendrá lugar ineludiblemente si no aparece una entidad superior que detenga el proceso acumulativo de desgracias sociales. Irene Vasilachis de Gialdino llama “contexto catástrofe” (2007) a esta atmósfera cognitiva instalada por la hipérbole que representa "en realidad" los sueños de intervención social/autoritativa propios del enunciador.

A su vez, la hipérbole descansa y viraliza moralidad nativa, pudiendo llegar a la situación de creación de “pánico moral” (Thompson, 2014). Para comprender esta posible transición, nótese en la intervención que transcribimos la repartición de los roles semánticos, que hemos de entender, grosso modo, como el papel relacional -valga la redundancia- adjudicado a quienes el discurso dice que forman parte de un drama social particular. "Todos los argentinos" (sic) son puestos en un papel pasivo, "el estado argentino" (sic) en un rol obligado de proveedor insensato, "la UBA" (sic) como un agente activo de políticas educativas ilegítimas (que vuelve torpe al estado) y "los estudiantes extranjeros" (sic) como agentes activos en su aprovechamiento de lo que el estado insensato les da. Sí: los estudiantes como agentes “activos”. Este y los demás informes los esbozan como dueños de una subjetividad que sabe desplegar inteligencia al solo efecto de aprovechar un vasto conjunto de recursos que no serían de su propiedad. Dadas estas condiciones (invasión demográfica, estado derrochador, políticas equivocadas e inteligencia usurera) la estafa moral para los nativos quedaría evidenciada.

Con estas jugadas enérgicas comienza el primer informe que analizamos. Para Patrick Charaudeau y Dominique Maingueneau (2005) la noción de estrategia del discurso incluye dos espacios, el espacio de las “restricciones" (que comprende el variable apego a las normas de un acto de lenguaje "sito" en un género discursivo) y el espacio de las estrategias propiamente dichas (que comprende las posibles "elecciones" de los sujetos respecto de la puesta en escena final de los actos del lenguaje). Estos autores sugieren que las estrategias deben atender simultáneamente tres frentes: el de la "legitimación” de la autoridad discursivo/moral del enunciador, el de la "credibilidad" en la verdad de lo que anuncia y el de la "captación" de la mayor cantidad posible de categorías de enunciatarios. Aplicado a lo visto hasta el momento, acaso podamos decir que la apelación a que "no nos sintamos culpables si nos interesa el país" (sic) da la autoridad moral, el juego de los números da la prueba de la credibilidad, y la presentación de "todos los argentinos" (sic) como los mantenedores de una universidad para extranjeros apunta a hacer entrar en su propio juego discursivo a un enunciatario-colectivo imposible de agrandar, un colectivo que ese mismo juego incita a que se autovisibilice como una entidad pasiva (bien visto: una víctima) respecto de lo que otras entidades (le) 
realizan.

Estos elementos fuertes presentes en el inicio del informe de PPT ayudan a imaginar cómo pueden seguir las argumentaciones en torno a la migración reciente ya que cumplen con la noción de presupuesto, central en cualquier situación y contexto comunicativo. En términos teóricos, es útil presentar lo presupuesto por los hablantes como los elementos iniciales de un juego con resultados que nunca pueden predecirse del todo. Justamente, si tiene sentido hablar de las movidas del lenguaje es porque comprometen a un análisis empírico que busque los grados variables en que los intercambios lingüísticos se apegan o confrontan con los presupuestos presentados. En efecto, es dificultoso imaginar una conversación que empiece sin presuponer nada acerca de algo. Al contrario, las conversaciones presentan puntos de referencia, unidades de medida, respecto de las cuales anclar la tematización. Parecidos a las movidas del juego del ajedrez, los enunciadores ponen a sus enunciatarios (presentes y ausentes, reales e imaginados) ante una situación que ellos no crearon y en la cual, no obstante, deben inscribir una respuesta: ¿cómo moverse desentendiéndose de la movida previa? Para nuestro caso: ¿cómo hablar sobre los migrantes recientes sin tener en cuenta los fuertes puntos de partida presupuestos en los informes periodísticos? Leemos en Oswald Ducrot:

Cuando un enunciado implica presupuestos, despliega entre los interlocutores un mundo de representaciones consideradas como evidentes. Instituye desde ese momento un universo intelectual que se transforma en el telón de fondo del diálogo. Los presupuestos de una oración son como una especie de contexto no exterior sino inmanente que el enunciado acarrea simultáneamente a sus informaciones propiamente dichas. (Ducrot, 2001, p. 15)

Estamos ante una afirmación interesante, es claro. No obstante, luego el autor nos aclara que el enfrentamiento de subjetividades -pareciera que de eso trata "estructuralmente" lo presupuesto- "se nos aparece (...) como una ley fundamental del lenguaje, no solamente por razones psicológicas o sociológicas sino en virtud de una necesidad que inscribe en el sistema mismo de la lengua” (Ducrot, 2001, p. 27). En el contexto de este escrito, quedarnos sin más con esa afirmación desviaría nuestra atención. ¿Por qué? Porque lo que deseamos destacar es el carácter sociológico de la fuerza con la que pueden operar ciertos presupuestos, lo cual reenvía -como es debido- el análisis del uso del lenguaje a la problemática de la distribución desigual de autoridad epistemológica de los enunciadores sitos en un campo de disputas por el sentido.

Un presupuesto, si funciona "bien" en un campo discursivo desigualitario, tiene la capacidad de hacer pensar que quien lo impugne ha quedado fuera de la conversación misma. Volvemos a Ducrot:

La noción de presupuesto (...) se encuentra en la base de un tipo de discurso particular, que es el par pregunta-respuesta. Un enunciado, afirmativo o negativo, B, puede ser considerado como capaz de responder a una pregunta A solamente si B conserva los presupuestos de A. (2001, p. 24).

Da un ejemplo que no cumple esta condición: “- ¿Pedro fue a París en avión?” “-No, no fue a París.”. En este plano, si alguien pregunta “¿Sabés cuántos extranjeros se atienden en salas de hospitales de municipios de la provincia de Buenos Aires? 340.000”, y otro responde: “depende de la organización que se de en los hospitales”, y otro: “depende de la política pública en salud”, no estarían respondiendo, en realidad, ya que no están reconociendo el presupuesto del preguntador con autoridad para quien 340.000 es "muchísimo" (sic). Si éste fuera el caso, quien responde borraría de un plumazo toda la conversación que pudo haberse dado y que era -dicho no sea de paso- la única conversación posible; esto es algo que -veremos- no ocurrirá. El presupuesto "muchísimo" (sic) en la salud pública, que encuentra ecos en la situación universitaria, oficia como unidad de medida infalsable para la continuación de los intercambios.

\section{JL: Porque en la salud ¿cómo son los números?}


Es la pregunta que hace el conductor a la coconductora luego de agotar en diez minutos el tema migrantes y universidad. Entonces se inauguran con una intensidad nada menor diez nuevos (y últimos) minutos. Enseguida lo notaremos: el discurso sigue encaminado en contornear la imagen de los migrantes para hacerla reconocible dentro de la categoría de los usufructuantes del dinero público que proviene del pago de los impuestos por parte de "todos los argentinos" (sic).

No obstante, se notará cómo la imagen aparece agravada, ya que la idea del aprovechamiento es casi escandalosa al producirse en un contexto de "emergencia” (sic) que, según la coconductora, ameritaría que la atención sanitaria se destine solamente a los "propios" (sic). Del escándalo a la inmoralidad hay un solo paso: conductor y co-conductora imputan a los migrantes inteligencia organizativa para el aprovechamiento de los recursos. Los roles semánticos se repiten: inmigrantes como agentes activos y el pueblo bonaerense como agente pasivo del espectáculo de la invasión en pleno estado de emergencia sanitaria. Y también se repite el temible juego de los números -tan eficiente en términos cognitivos- por medio del cual los enunciatarios no tendrán elementos para saber a qué personas y a qué situaciones refiere el universo de los 340.000: ¿son extranjeros calculadamente ocasionales, son extranjeros sin documentos deseosos de vivir en Argentina, son habitantes del país nacidos en el exterior?

RM: Teniendo en cuenta que hay emergencia hospitalaria para los propios bonaerenses... ¿te acordás que en su momento hubo un tole tole cuando Macri estaba como jefe de gobierno porteño y Scioli diciendo por qué vienen a atenderse a los hospitales porteños? Bueno, mirá estos números: ¿̇sabés cuántos extranjeros se atienden en salas en hospitales en municipios de la provincia de Buenos Aires? 340.000.

\section{JL: 340.000, es mucho.}

\section{RM: 340.000 extranjeros, es muchísimo.}

JL: Ahí, me contaban el otro día en la radio, hay tours médicos... sí de los países limítrofes a la Argentina $\dot{i}$ me entendés? hay gente que viene a operarse de algo. Vienen, garpan acá un par de días, se operan y se vuelven.

RM: Todo esto cuesta, obviamente, todo esto tiene un costo que no se paga, quien puede pagar un bono lo paga, quien no, no. Pero no estamos hablando de un estado ideal donde los propios bonaerenses puedan entrar a las salas o a los hospitales municipales a atenderse, sino que hay un déficit enorme; hay una emergencia que están tratando de ver cómo la subsanan y mientras tanto están subvencionando de alguna manera los $\mathbf{3 4 0 . 0 0 0}$ extranjeros. Se organizan como decía Jorge, porque uno puede hablar de cosas más superficiales como cirugías estéticas que se hacen algunas, reparadoras, estéticas en hospitales bonaerenses... no, estamos hablando de cirugías programadas que no pueden hacerse en los países limítrofes y que vienen a hacérselas acá.

Pero los “340.000” (sic) extranjeros que se realizaron “592.000” (sic) prácticas médicas no son solamente un misterio porque los enunciatarios no tienen posibilidad de categorizar en proporciones por actividad médica ese universo absoluto. También las cifras son un misterio porque tranquilamente se puede sospechar que lo que el informe da a entender no se haya cumplido: que esas prácticas médicas se hayan realizado en tiempo y forma, además de gratuitamente.

Es notable cómo en muchos debates sobre la migración reciente se habla con énfasis de instalar entre los Estados mecanismos de reciprocidad y compensación, y cómo también se pide a los migrantes que hagan algo acorde. Queremos decir: sean los Estados o sean las personas, se tiene el reclamo generalizado de que todos se sometan a un entramado de derechos y obligaciones. Si un Estado de acogida da salud, que el 
Estado de origen le gire dinero o dé salud a los nativos si allá la necesitan; o si un migrante tiene salud acá que acepte las reglas del juego propias de la sociedad benefactora. Parecido a la figura del "entimema" (Charaudeau y Maingueneau, 2005) nos encontramos aquí con un razonamiento falaz constreñido a "callar" unas premisas que, de decirlas, llevarían probablemente al oyente a realizar una inferencia distinta. Lejos de ello, tenemos que en todos los casos se impone un presupuesto que no se puede comprobar pero que tampoco se puede falsar: que el Estado "ya” dio salud, que los migrantes “ya” gozan de ciudadanía, que la sociedad de acogida "ya” cumplió, dando todo. Se dice de un entimema que se guarda información o que no la da porque no es necesario, ya que el sentido asumido en lo que finalmente dice lleva intacto aquello que ya está en la mente de los interlocutores (nosotros, los argentinos, “ya” cumplimos). Importante: adviértase, por un lado, la asimetría relacional presupuesta (los que no cumplen no somos nosotros) y, por otro, y el cuidado de la imagen de sí o la autopublicidad que de la sociedad de acogida hace el enunciador, convertido en su representante.

ET: Sabés que yo tengo mucho interés en el tema de la salud que me interesa especialmente y tenés un dilema. Hay municipios, creo que Tigre o San Isidro, que tenés que mostrar el ABL del distrito porque si no no te atienden.

\section{JL: Eso a mí me parece mal.}

ET: Y hay otro que es el de la ciudad de Buenos Aires que es universal. Venga alguien de China popular o de Taiwán a atenderse lo tenés que atender, entonces no hay forma de satisfacer esa demanda porque tenés una demanda infinita, y cuando ponés una aparatología nueva es peor todavía y crea más demanda y entonces te sirve menos. Entonces vos ¿cómo hacés? Sos el intendente de San Martín, que es uno de los casos ¿qué hacés? ¿dos hospitales, diez hospitales, cincuenta? No dan abasto.

JL: Creo que hay que diferenciar. Si las personas viven acá, esto es un país. Esto no es el municipio tal contra el municipio tal, o la provincia tal contra la provincia tal. Somos un país y el país es entero. (...). En el caso de los extranjeros si son cientos de miles lo que hay que plantear es una compensación de estado a estado.

\section{ET: Yo tiendo a estar de acuerdo con vos, pero es un lío porque no das abasto.}

La intervención que acabamos de leer pertenece a otro co-conductor que sale en auxilio de la co-conductora a quien pertenece la intervención anterior. Se trata de un apoyo teatral que el primero otorga a la segunda y, aunque no da cifras, argumenta con una cadencia bastante parecida a la hipérbole. Difícil sustraerse a la imagen del desborde y la inundación de los hospitales públicos (otra vez: el "contexto catástrofe”), tanto como a imaginar que ello ineluctablemente ocurrirá si no aparece una entidad con capacidad de decisión para obturar el acceso a la salud (otra vez: los sueños de autoridad prohibitivos de los enunciadores).

Interesante: se produce un intercambio de opiniones contrastantes sobre un fondo común. Se comparte la necesidad de la compensación entre Estados pero el conductor interpone una corrección conceptual a los coconductores, que sostienen la idea de que un ciudadano podría aspirar a la salud bajo una condición: mostrar el impuesto municipal que atestigua que vive en una comarca determinada. Lanata, a través de una movida argumentativa que los deja prácticamente sin capacidad de respuesta (y a la derecha de todos los discursos de derecha escuchados por aquellos días), mantiene el criterio del pago de impuestos pero resalta que, cuando existe un país, la salud es un derecho con independencia del lugar de solicitud.

El co-conductor manifiesta tener un dilema, algo que pareciera no ser cierto. Veamos: un "dilema” refiere a una situación cognitiva de estancamiento e indecisión. Por ejemplo: está en un dilema quien, al pensar que 
“a” es la solución para "z" concluye que los costos de aplicar "a” son, al menos en este momento, elevados. Piensa entonces que la solución puede ser "b”, pero concluye asimismo que tampoco aportaría nada bueno. Luego imagina “c” y, por el motivo que sea, piensa que la solución a "z" no llegará. Por lo tanto, nada puede hacer en relación al problema que le quema la mano. Está en un dilema quien piensa: ¿qué hacer si las alternativas imaginables no son satisfactorias? (Charaudeau y Maingueneau, 2005;

y Meccia, 2006). Si alguien piensa: "sin ti no encuentro mi camino y contigo me perdí” está, efectivamente, en un dilema porque por lo menos dos alternativas se le presentan insatisfactorias y, en consecuencia, no hay salida.

No sería éste el caso del co-conductor, que enmarca su intervención con esa noción pero acaso lo haga como una estrategia de cuidado de la propia imagen, o como eso que los estudiosos de las interacciones del habla llaman estrategia de "atenuación" (Charaudeau y Maingueneau, 2005). En pocas palabras: si el enunciador va a atacar en los próximos turnos de habla, intentará demostrar en los turnos anteriores que esa no es su naturaleza.

¿Por qué no hay dilema real? Si todo dilema presenta salidas a explorar (remarquemos el plural) que luego se concluyen falsas o inoportunas (remarquemos el carácter comprobatorio de la temporalidad), la intervención que analizamos presenta ex ante una única salida posible (una comarca no puede tener un sistema de atención de salud universal, menos aún para migrantes), con lo cual no hay dilema, puesto que la situación de tensión cognitiva tiene una sola pata. En rigor: no hay tensión; al contrario: todo el argumento del coconductor demuestra cómo tomó partido por anticipado y, en consecuencia, que no está tironeado por ninguna otra opción, condición mínima de una situación dilemática. Vuélvase a la intervención: si, sea como sea, la atención universal de la salud en una comarca será deficitaria aun construyendo "50 hospitales” (sic), las cosas serán un "lío” (sic) porque "no das abasto ” (sic) entonces no hay dilema: hay una nueva conclusión que recoge el presupuesto del contexto catástrofe.

El informe de PPT termina con el llamado al "sinceramiento" que mencionamos al principio: estamos en el momento para hablar de todo como sea, por más que duela, dejando a un lado la "hipocresía" (sic) porque, bien vistos, los temas que los enunciadores están tocando "no resisten mayor análisis” (sic). Si, como vimos desde el punto de vista de Oswald Ducrot, la cuestión migratoria ya cargaba con los presupuestos de la “invasión” y del “usufructo”, aquí podemos observar -y observaremos después- cómo se le sobreimprime el "momento del sinceramiento" como un presupuesto mayor (o un metapresupuesto). Es más, en realidad, quien recorra la mayoría de los debates políticos posteriores a diciembre de 2015, lo encontrará como "santo y seña” para la entrada legítima en lo que se debe conversar. El santo y seña es uno solo, quien no se pliegue a él, no tiene posibilidad de entrar en el intercambio informativo:

RM: Hay una discusión muy hipócrita porque acá estábamos discutiendo si íbamos a atender... (se refiere a si los hospitales de la Ciudad Autónoma de Buenos Aires atenderían a ciudadanos residentes en la provincia de Buenos Aires)

\section{RM: Son casos que no resisten mayor análisis.}

RM: El discurso lindo mientras vos decís “pago mis impuestos”. Bueno, yo pago para que se atienda cualquiera y si vas a cualquiera de los hospitales no te pueden atender porque están atendiendo a un montón de otra gente. En el momento de atender, tenés la cola a las cinco de la mañana, ahora lo hacen por teléfono, cuando llegás y no te podés atender, sabés cómo no te gusta que estén atendiendo a otros... se dice poco.

"Se dice poco" (sic) de lo que se debe decir, poco acerca de lo que el contexto -a propósito, un concepto que desarrollaremos en el próximo apartado- amerita y exige. Pero los periodistas, como haciéndose cargo de una 
imaginada misión histórica, dicen de todo. Fijémonos cómo lo hace también un encumbrado dirigente político.

\section{Importar la Resaca}

El programa $P P T$ que acabamos de analizar fue el primero que trató la inmigración reciente de una manera tan decidida. Desde la perspectiva de la "agenda setting” (Mc Combs, 1994) es posible postular que representó el inicio de un "ciclo" de tratamiento del tema, esto es: que marcó la agenda sucesiva en los medios de comunicación y muy probablemente agregó un punto de relevancia más en el pensamiento de una franja significativa de la sociedad.

Como sabemos, el enfoque postula la emergencia de paralelismos entre aquello que los medios dicen que pasa en la sociedad y lo que la gente piensa que pasa. Aunque la teoría de la "agenda setting" dice que no se pueden adelantar los significados con los cuales el público investirá el punto de relevancia, es un indicador incontestable del poder de los medios de comunicación la misma relevancia social adquirida por los eventos que la agenda mediática destaca. En nuestro caso, el "problema” de la inmigración adquirió una importancia comparable con los otros grandes temas de la agenda mediática y social de ese momento en Argentina (corrupción e inseguridad, los principales).

Es en este contexto que -como parte del ciclo- aparecieron las declaraciones de un senador perteneciente al Frente para la Victoria, el partido político que había sido oficialismo durante los doce años anteriores:

MAP: En la provincia de Buenos Aires hay un proceso de decadencia, una consolidación de pobreza y migración; es un tema del que nadie quiere hablar porque son todos políticamente correctos. El peso del narcotráfico en la Argentina creció de manera importante. (...).Los militares no pueden intervenir en tareas de seguridad interior. (...) Sí pueden realizar tareas de apoyo y reemplazo en frontera. Me parece que es una cuestión que la Argentina tiene que controlar porque hay una inmigración muy compleja. $\underline{6}$

En esta breve intervención encontramos una resonancia agravada del conjunto de significados propuestos por PPT. "Resonancia" porque el enunciador exhorta a hablar con "sinceridad", por fuera de lo "políticamente correcto" y "agravada” porque postula una asociación directa, carente de atenuadores lingüísticos, de la inmigración reciente con el narcotráfico y la delincuencia.

Más arriba habíamos sugerido que el estudio de las formaciones discursivas (Foucault, 2008) suponía poner en evidencia las rejillas de especificación, por medio de las cuales la misma formación habla sobre un fenómeno, y que -desde un punto de vista metodológico- esa tarea se enriquecía si adoptaba una perspectiva diacrónica. Bien: la intervención del senador sirve en los dos sentidos: primero, porque vuelve a especificar el fenómeno en términos negativos, y segundo, porque "dialoga" con lo que PPT (y sus enunciadores satélite de los días posteriores) habían puesto a circular en el espacio discursivo.

Justamente, cuando la visibilidad del objeto propuesta por una rejilla comienza a repetirse, es momento de pensar que -tal vez- una formación discursiva se encuentra en estado operativo, ya que de un conjunto de textos (sin importar el género) es factible señalar ciertas marcas cognitivo/axiológicas que hacen a su producción y -más importante- a su aceptabilidad por parte de las sensibilidades sociales medias. Al respecto, puede sernos útil la distinción que nos recuerdan Charaudeau y Maingueneau respecto de la cohesión y la coherencia de los textos: la primera es una propiedad lingüística de los mismos, la segunda, por el contrario, es social:

resulta de un juicio que toma apoyo en el conocimiento de la situación y en los saberes (...) de los 
sujetos. M. Charolles eleva la necesidad de coherencia a principio general de interpretación, forma a priori de la identificación de un conjunto verbal como texto. (2005, p. 88)

Interesante para remarcar en un escrito sobre formaciones discursivas relativas a la inmigración reciente en Argentina, la coherencia de estos discursos no es una propiedad a priori sino un "logro" conjunto (Garfinkel, 2006) de enunciadores y enunciatarios que no puede sino apoyarse en la propuesta cognitivo-moral que supone la rejilla especificadora. La rejilla de la formación crea atmósferas interpretativas, pone en escena actancias con subjetividades y acciones características, delinea escenarios donde el desenvolvimiento de los dramas sociales es predecible. Y es esa predicción, precisamente, el indicio de que el conjunto de textos circulantes es coherente. Todo ello ocurre en la realidad de la enunciación, ese espacio cognitivo donde los sujetos "saben" demasiado.

Sigamos con el discurso del senador y observemos como prácticamente todo se repite. Los roles semánticos son los mismos (nativos pasivos versus extranjeros activos que ocupan), el "contexto catástrofe” sigue siendo ominoso (¿cuánto más puede aguantar un país que recibe inmigrantes pobres si no intervienen las autoridades?), también se reiteran la apelación a la sinceridad de los ciudadanos (superadora del sesgo políticamente correcto del pensamiento massmediático) y la autopublicidad que implica la exhortación a que Argentina pida compensación a los estados limítrofes, como si efectivamente ya hubiera dado -en tiempo y forma- el derecho a la salud que los migrantes necesitan:

MAP: Michel Rocard, líder socialista, que fue ministro de economía de Mitterand, dijo en el año 1980 una frase que podría haber sido imputada a Le Pen, al Partido Nacional: “¿cuánta miseria puede aguantar Francia recibiendo migrantes pobres?” Esta es una pregunta que yo reflexiono y me hago también en la Argentina. (...). Acá uno corre siempre el riesgo de que le pongan la etiqueta. Yo creo que uno de los principales problemas de la Argentina es la cultura igualitaria, y fundamentalmente un pensamiento que en los medios de comunicación es políticamente correcto, digamos. Siempre funciona el esquema de esa manera. (...). Hablando con un médico del Hospital Rivadavia me dijo que todo el mes de noviembre estaba ocupado por ciudadanos que vienen del Paraguay a operarse e intervenirse y no hay ningún tipo de reciprocidad. (...). En Chile pasa exactamente lo mismo. Si uno se enferma en Chile o tiene un accidente en la ruta, si no tiene la tarjeta.

Hace un momento, cuando nos referimos a la noción de estrategia del discurso, dijimos que la misma debía moverse entre tres lógicas: la de la legitimación, la de la credibilidad, y la de la captación. Respecto de la primera, aquí también tenemos repetición: si lo "políticamente correcto" oficiaba como una cortina de humo de la realidad, levantarla convierte en legítimo cualquier tema, por más crudo que sea su tratamiento. Respecto de la tercera, al afirmarse que "nosotros” funcionamos permitiendo que otro país haga su propio ajuste social y delictivo, se tiende a captar como enunciataria a toda la sociedad argentina, y por lo tanto, también tenemos repetición.

Sin embargo, en el párrafo anterior y en los dos siguientes aparece una novedad respecto de la credibilidad. A diferencia de $P P T$, en las intervenciones del senador no aparece como recurso de autoridad epistemológica el “juego de los números" sino que la forma de hacer creer elegida es proponer que los enunciatarios dejen de mirar la propia decadencia y dirijan la mirada hacia el exterior. En efecto, las experiencias de otros países pueden oficiar de instructivas lecciones: así, el senador hablará de los infortunios que la migración ha causado en otras naciones, o sobre lo que han dicho personajes desconocidos para la población pero elevados al rango de expertos inapelables, o denunciará cómo otros países -inteligencia diabólica mediante- han resuelto sus problemas internos exportándolos como emigrantes.

MAP: Lo que digo es que tenemos que dejar de ser tontos. Está cambiando el mundo, es un 
mundo más complicado, es un mundo que se cierra. Hay que mirar la lectura internacional. (...). Todo el mundo políticamente correcto dice que va a ganar Hillary. ¡Cuidado! Cuidado porque la gente de Detroit que tienen la fábrica cerrada porque se fueron a China, el sector blancoamericano que quedó postergado por la cuestión laboral, por la pérdida de empleo, no piensa de esa manera.

(...)

MAP: El problema es que nosotros funcionamos como ajuste social de Bolivia, es muy interesante. Y de ajuste delictivo de Perú. Es interesante, es realmente interesante el tema. Casi apasionante, le diría, porque Perú ha resuelto su problema con la seguridad. Ha transferido todo el esquema narcotraficante. Las principales villas de la Argentina están tomadas por peruanos; y por argentinos cómplices de peruanos, porque tampoco quiero discriminar. Lo que digo es que ellos resuelven el problema desde el punto de vista de su realidad mejoran incluso el mejoramiento de sus propios países y la Argentina incorpora toda esta resaca.

En estas intervenciones del senador puede notarse cómo se pone en juego, a los efectos de la credibilidad, una cláusula argumentativa "global-local" que, además de poseer autoridad epistemológica, permite hacer frente al gran problema denunciado, a ese gran escollo para hacer frente a los problemas del país que es lo "políticamente correcto" (sic) y la “cultura igualitaria” (sic). De esta manera, las intervenciones buscan delinear un estado de situación mundial que opera con la irresistible fuerza de un vórtice al que sólo puede darle la espalda un país que resiste tozuda e irracionalmente porque tiene dirigentes "tontos" (sic) de idearios garantistas. Por cierto, un lugar común en las ideologías “desideologizadas” propias del neoliberalismo. Y semejante resistencia, a pesar de tener ante los ojos lecciones fácticas y concretas de lo más "interesantes” (sic) y “apasionantes” (sic). ¿A tanta ceguera puede conducirnos la “cultura igualitaria” (sic)?, sería el metainterrogante de las intervenciones del senador.

Por último, no es un detalle menor la cadencia funcionalista que rige la última intervención, en la que se habla de la "incorporación de la resaca" (sic). Hablar en este contexto de resaca supone referirse a una consecuencia inevitable de la operatividad de ciertos mecanismos de una sociedad, una operatividad que produce excedencias y sobrantes perjudiciales para su funcionamiento. ¿Qué podría decirnos un analista funcional? Que la misma sociedad de origen deberá generar los procesos de neutralización o "metabolización" -permítasenos la metáfora- de la sobra amenazante. Sin embargo, la cadena de funciones se corta por la torpeza de otros países llenos de "tontos" (sic), narcotizados por el pensamiento “políticamente correcto" (sic) y la "cultura igualitaria” (sic) que no tienen inconvenientes en hacer de la resaca inmigración, atentando contra los requisitos funcionales de sus respectivas sociedades que, tarde o temprano, comenzarán a funcionar mal. Así, el metamensaje sería que no hay sociedad que pueda aguantar esa población que, por lo tanto, queda condenada a permanecer en el aire como una pelota golpeada por todos en todas partes, en el marco de un juego de ping-pong sin mesa y sin fin. Si son "resaca” (sic) no tienen tierra: sobran allá y no deben importarse acá.

Deseamos cerrar esta segunda parte con más reflexiones metodológicas; otra vez, destacando la utilidad de una modalidad diacrónica de exposición y análisis de la información. Ya dijimos: las formaciones discursivas filtran los fenómenos a través de sus rejillas de especificación. Para hacerlo despliegan múltiples estrategias discursivas que movilizan recursos lingüísticos variables e impredecibles. En definitiva, las formaciones discursivas disponen de e inventan formas de "hacer ver" aquello de lo que habla. Cuando analizamos el programa PPT trajimos -aunque modificada- la noción de framebridging de David Snow et al. Sucintamente, para hacer entrar en tema a los enunciatarios, o para encenderles -cognitivamente hablandouna alarma, las intervenciones tendían un puente entre categorías de personas que la formación considera 
usureras del erario público: los estudiantes universitarios argentinos y extranjeros de las clases medias; tras esa asociación llamativa (efectista para “ver” la situación), también se hablaba de los migrantes que usaban los servicios públicos de salud. Lo que pudo escucharse quince días después en el programa La mirada no sería exactamente lo mismo; tal vez ahora convenga utilizar otra noción de Snow et al.: la de frameamplification (1986).

Un discurso, en determinada situación comunicativa (y asimismo a los efectos de alarmar), más que proponer conexiones entre categorías de grupos o personas, puede amplificar la creencia o el valor de algo, puede dibujar la situación social relativa a ese algo, más que presentar al elenco social de esa situación: sea porque ese algo es valioso y está amenazado o porque ese algo es disvalioso y se encuentra en estado de expansión, lo cierto es que el discurso desespera en hacer ver y hacer creer en el valor, a menudo a través de intervenciones estereotipadas. Para Snow et al. se amplifica una creencia no desconocida para la gente que, en tanto que tal, contiene "un conjunto de relaciones presumidas entre dos cosas o entre algo y una característica, tal como se ejemplifica en las presunciones «como Dios está muerto, la segunda venida es inminente», «los capitalistas son explotadores» y «black is beautiful»” (Snow et al., 1986, p. 469). De este ejemplo a la insistencia del senador respecto de la importación de narcotráfico y delincuencia vía migración hay una distancia corta: existe un peligroso disvalor en expansión social a causa de la tontera de los nativos.

Es a través de estas estrategias (que incluyen tácticas y movidas menores) que las formaciones discursivas van creando los contextos de la comunicación. Prestemos atención: el investigador necesita una concepción móvil y multidimensional de contexto que puede desplegar solamente mediante la consideración diacrónica de las sucesivas realidades enunciativas. En efecto, el contexto para hablar de migración reciente en Argentina debe ser temporalmente ubicuo ya que: contexto existe tanto en el inicio de este ciclo discursivo, como en todos sus momentos intermedios y también existirá en su momento final, que podrá ser utilizado como contexto en el inicio de otro ciclo discursivo sobre migración u otro objeto con el que lo emparente el pensamiento hegemónico. Pero contexto también lleva el análisis “afuera” de las cosas que sucesivamente se dijeron: contexto es también el ciclo político inaugurado en diciembre de 2015, la legislación argentina sobre inmigración, la situación económica argentina y latinoamericana, la guerra mediática librada entre adherentes al gobierno anterior y al actual, el género discursivo del programa televisivo en el cual se intervenga, y hasta el prestigio relativo que tengan las personas que participan en los programas de televisión, entre tantos otros factores. ¿Qué contexto constriñe, regula más lo que se dice? ¿Cuál es el contexto más importante? Son éstas las preguntas que ameritan una respuesta para cada momento.

$\mathrm{Al}$ respecto, Charaudeau y Maingenueau escribieron que el contexto es

el lugar donde se encuentran los datos externos que cumplen la función de restricciones de imperativos, los cuales determinan lo que está en juego en el intercambio, proviniendo tales imperativos a la vez de la identidad de los participantes y de la ubicación que ocupan en el intercambio, de la finalidad que los asocia en términos de mira, del asunto que puede ser convocado y de las circunstancias materiales en las que se realiza. (Charaudeau y Maingeneau, 2005, p. 533).

Por su parte, Teun Van Dijk propone que el contexto no es regulador discursivo apriorístico sino que se forma "mediante una interpretación estratégica de los eventos actuales, así como también de la instanciación del conocimiento general socialmente compartido de los acontecimientos.” (Van Dijk, 2012, p. 116).

Acaso podamos representar el contexto de un discurso con la imagen de una caja china: es "una” pero a condición de que tenga varias en su interior. Respecto de la migración reciente en Argentina acaso uno pueda decir que el contexto es el ciclo político que comenzó en diciembre de 2015, pero a condición de que el análisis visualice los otros contextos que operan eficientemente en paralelo a él. Parece una frase simple pero es la más compleja: "todo es contexto". 


\section{Un Tema Sensibe, delicado, áspero}

Intratables es un programa de opinión política con un formato bastante novedoso. Mirarlo deja confirmar la vieja hipótesis de que los géneros discursivos se doblan pero no se rompen expuestos, como están, a procesos de hibridación. Si buscamos una denominación, tal vez la que más le convenga sea "programa interactivo de opinión política”. Estructuralmente parece haber abrevado, en parte, en los talk-shows de la década del 90 y, en parte mayor, en los programas de chimentos del mundo del espectáculo que se pueden ver desde el inicio del nuevo siglo: se tiene un tema de debate (o una noticia convertida en tema de debate) y, en torno a los mismos, se ponen a hablar en vivo y en directo un conjunto de panelistas fijos del staff con un conjunto de políticos y/o referentes de distintos ámbitos y/o (en menor medida) damnificados por lo que se debate; todos “apenas” puntuados por el conductor, un muchacho joven, proveniente del mundo del espectáculo, de gran habilidad para que los intercambios se enciendan y exploten.

De esta forma, casi como si de un focusgroup se tratara, el programa da la apariencia de que, desde la interacción horizontal entre los panelistas, sale lo más verdadero que pueda decirse sobre el tema que sea. En este sentido, al oficiar apenas como facilitador de la verdad, le queda a los televidentes la imagen de un conductor antienciclopédico y neutral, de alto contraste con la enorme mayoría de los periodistas del medio televisivo (por ejemplo, todos los que hemos mencionado aquí), portadores de un estilo enciclopédico, omnisciente e inquisidor. Estos periodistas lo dicen todo, el conductor de Intratables, al contrario, le hace decir todo a sus panelistas e invitados. A esta cualidad contribuyen, sin duda, su juventud y la plasticidad de su habla.

Como es de prever, en esta última parte del escrito recorreremos algunas intervenciones. No nos será nada difícil reencontrar lo que ya hemos visto en PPT y La mirada, por lo que nuestros comentarios serán breves. Donde sí nos detendremos -aunque también es una iteración- es en la desesperada y hasta agresiva exhortación a ser "sincero" (sic) y a no ser "hipócrita" (sic) para discutir (de la única manera en que se podría discutir) el tema migratorio. En verdad, lo que desearemos analizar es si, hasta este momento, dentro de los géneros a través de los cuales se escenifica gradualmente la formación discursiva sobre migración reciente, existe realmente una “discusión” sobre el tema, o qué, si este no fuera el caso. Que la migración reciente fue entronizada como objeto de intercambios polémicos es algo sobre lo que no podemos dudar; ahora, que la forma tomada por la polémica sea la “discusión” será precisamente, para nosotros, materia para la discusión de esta última parte.

Las cámaras muestran a los referentes y al panel de Intratables. El conductor, energizado, siempre sonriendo, nunca sentado, comienza con su tarea. Como telón de fondo (otra forma de “contexto”, además de los programas que ya hemos analizado), están unas pantallas gigantes que de modo permanente mostraban la Villa 31 de Retiro desde una panorámica superior. La villa: una auténtica transnominación de la migración reciente, a pesar de las disculpas y las fórmulas de cortesía lingüísticas del conductor y los panelistas.

Fórmulas de cortesía es una idea de raigambre goffmaniana $(1970,1974)$ que se encuentra aplicada en los estudios etnográficos sobre la conversación. Alude a las formas en que los participantes de una interacción hacen lo posible para mantener el equilibrio ritual consistente en no maltratar o no desconsiderar directamente a los demás a pesar de lo que piensan.

Muchos encuentros sociales cara a cara, y entre ellos los intercambios discursivos, se asemejan a una guerra fría: los participantes son enemigos y, sin embargo, no pasan directamente al ataque: antes tienen que dar la impresión de que manejan reglas de respeto y sentido de la deferencia. Por supuesto, el grado de manejo de estos códigos depende de quienes sean los interactuantes y de cuál sea el objeto de referencia: está bien estimar que a medida que se desciende de la escala social su aplicación disminuya proporcionalmente. Observemos en los siguientes fragmentos al conductor, repitiendo una y otra vez la fórmula. Teun Van Dijk (2003) ha llamado disclaimers a estas movidas in situ del lenguaje. Son como pedidos anticipados de 
disculpas por lo que se dirá.

Empieza el programa, el conductor instala el tema como un problema grave y, en el mismo acto de habla, pide "disculpas" en forma de pregunta, como aquellos enunciadores que antes de hablar mal de los gays o los judíos se preguntan y (auto)responden que todos tenemos amigos pertenecientes a esas potentes categorías imaginarias y que, en consecuencia, una acusación contra él es inválida:

SDM: Nada más que un tema muy sensible, muy delicado que es la inmigración. ¿'Todos somos hijos de inmigrantes, no? ${ }^{7}$

OFF: Las polémicas declaraciones de Pichetto destaparon una olla a presión que caló hondo en la sociedad.

SDM: Vamos a ver lo que dijo ayer Pichetto. Me parece que pone en discusión un tema muy sensible, muy delicado y teniendo en cuenta que somos todos hijos, nietos de inmigrantes, o bisnietos, no. ¿Qué pasa con esta discusión no solamente en Argentina sino en el mundo entero? Mirá.

SDM (Luego del informe:) Ahora, una política migratoria no tiene nada que ver con la xenofobia.

SDM: La verdad que lo que Pichetto dice instala un tema muy, muy áspero, y que hay que legislar, hay que ordenar.

SDM: Yo soy hijo de inmigrantes. Mi papá es portugués. (...) Todos somos.

PV: Acá no estamos discutiendo los laburantes, los que trabajan en las quintas y tienen una conducta intachable. No hay que ser hipócrita.

Este conjunto de intervenciones de cortesía se pierden a medida que se suceden los turnos de habla siguientes. Pueden también ser consideradas atenuadores porque procuran cuidar la imagen del enunciador. La mayoría parecieran ser atenuadores de “concesión aparente” (Van Dijk, 2003). Veamos.

La migración es un "tema sensible” pero no hay delicadeza en afirmar que lo que obtienen los inmigrantes va “en desmedro" (sic) de los habitantes "puros” de un país (sic); se declama la separación entre migración y delito pero se muestra todo el tiempo en pantallas gigantes una villa de emergencia (recordemos al senador: "Las principales villas de la Argentina están tomadas por peruanos; y por argentinos cómplices de peruanos, porque tampoco quiero discriminar") y el conductor y los panelistas crean y recrean la "consecuencia" delictual en todo momento; la migración es un tema "sensible” (sic), debería tratárselo "delicadamente” (sic) porque "todos somos hijos de inmigrantes” (sic) pero el tema destapó una violenta "olla a presión” (sic). En suma, estamos ante un conjunto de intervenciones compuestas aparentemente como bivalentes: la lengua punitiva, antes de soltarse para castigar, necesita tramitar un atenuante teatral demostrando que tiene algo de mala conciencia.

Observemos lo que estamos planteando más en detalle en las siguientes intervenciones. En la primera, un referente legitimado por el contexto conversacional creado por el conductor y el staff se anima con una descripción demográfica de la situación de la migración en Estados Unidos. A continuación, en el marco de una movida discursiva restrictiva para el cuidado de la imagen ("una cosa es una cosa, otra cosa es otra cosa”), el conductor exhorta a que no se mezclen los planos de la “discusión”: migración no es delincuencia. Pero lo interesante es que el predecesor habló de demografía e inmigración y él responde en términos de delito e inmigración, aunque sea para negarlo. En la segunda intervención, el conductor pide un "cierre” a un abogado de gran prestigio, integrante del tribunal que juzgó a los militares genocidas en el histórico juicio de 
1985. Como veremos, el cierre inducido por quien había dicho que era una "locura” (sic) unir migración y delito, es ferozmente unidimensional: pregunta, obsesionado, por esa conjunción. En la tercera, sobre el final, una panelista presenta un porcentaje para decir que "no es el problema el tema del delito" (sic) cuando las implicaturas creadas por el resto del programa habilitaban casi obligadamente una lectura contraria. En fin: pareciera que nos encontramos ante un mismo movimiento del lenguaje contradictorio que acaso resuma un dicho popular: "tira la piedra el mismo que esconde la mano":

(1) PR: El porcentaje por primera vez, vengo de estar en Washington la semana pasada, por primera vez en los Estados Unidos el año que viene las salitas de cinco años va a haber por primera vez más chicos hispanos, latinos, afroamericanos, caucásicos (como ellos llaman a la inmigración blanca de otros países) en desmedro del norteamericano puro. Por primera vez más chicos en los jardines de cinco años van a no ser norteamericanos de pura cepa.

SDM: Acá estamos mezclando todo. Una cosa, Paulino. Una cosa es la inmigración, otra cosa es el delito. Son dos cuestiones diferentes. Hay que hacer una política inmigratoria que no tiene nada que ver con la xenofobia. Es simplemente ordenar. Ahora, relacionar eso directamente con el delito es una locura.

(2) SDM: ¿Qué pasaría con el delincuente acá, en nuestro país, con la justicia? ¿Con el inmigrante delincuente? ¿Qué pasa?

RGL: Bueno, se lo expulsa. Está la posibilidad de la expulsión. Pero esto se vincula con la política de seguridad.

\section{SDM: ¿Qué le pasa si Usted va a otro Estado y delinque?}

RGL: Bueno, empecemos a separar las cosas. Una cosa es ser inmigrante, que podemos ser cualquiera de nosotros también y otra cosa es ir a delinquir. Separemos las cosas para empezar a ordenar.

(3) DB: La estadística da cuenta de lo que están diciendo. Solamente el 7\% de los delitos que se cometen en las fronteras de Argentina están cometidos por inmigrantes, de modo que no es el problema el tema del delito.

No obstante, para el autor de este escrito, lo más notorio de Intratables es el modo en que conmina a propios y ajenos a terminar con lo "políticamente correcto" cuando se habla sobre inmigración o cualquier tema, expresión que desde su cosmovisión, significa "hipocresía” (sic) y/o “emoción” (sic) que impedirían tener un pensamiento sopesado sobre las cosas, en especial, cuando de "marcar una prioridad para el argentino" (sic) se trata.

Cuando se inicia el bloque dedicado al debate se presenta un pequeño informe que recoge -condensadomucho de lo dicho durante las tres semanas anteriores. En el medio, aparece un periodista de otro programa que lanza la exhortación:

AL: Dejemos de tanta hipocresía porque hasta ahora era palabra prohibida. No se podía ni hablar del tema porque era INADI, xenofobia, discriminación... ¡macana! Es proteger los intereses de los argentinos. Estamos hablando del extranjero que no paga un impuesto.

Luego aparece, ya fuera del informe, uno de los panelistas en cuyos hombros se carga la ideología promedio de la emisión. En todas sus intervenciones se advierte una tenacidad única, en comparación con sus compañeros de piso y con los programas que hemos analizado, pidiendo que se hable en serio sobre el tema: 
PV: Yo creo que tenemos que ser sinceros y no darle un tono emocional porque si no vamos a ser todos unos desgraciados los que decimos algo en contra de las políticas migratorias. (...). Pero: ¿no están de acuerdo con que la política está muy desordenada? (...). Yo creo que hay un desorden migratorio. Yo conté que fui a Bolivia, me saqué una visa porque fuí a trabajar. Me pasé, me vinieron a consultar al hotel a ver si yo tenía necesidad de renovar la visa. Y yo en su momento dije: “¿eh? Ustedes tienen tres millones de compatriotas en la Argentina”. Me sonó medio raro pero me pareció que era lo lógico y lo justo porque yo puedo ir y puedo quitarle el espacio a alguien. Yo creo que hay un desorden, un descontrol. Acá hay cualquier cantidad de chicos colombianos, 35000, 35000 que estudian acá. ¿Saben cuántos argentinos tenemos allá? 1000. (...). Me parece que no hay que tomarlo tan tan emocional porque si queremos unir a los bolivianos, a los paraguayos, a los peruanos, tratémoslos bien. Acá todavía el fútbol los discrimina, tenemos que parar los partidos porque están en contra de los paraguayos y de los bolivianos. Acá, lamentablemente, muchas señoras que colaboran en las casas trabajando de servicios domésticas las tienen en negro y las destratan.

Vayamos por partes. Primero, repárese en que aparece la figura del invasor y del usurpador, pero eso no es nuevo. La novedad es que el enunciador hace una especie de role playing cuyo escenario es otro país a través del cual quiere ejemplificar una idea parecida al imperativo categórico kantiano: en efecto, ofreciéndose como ejemplo vívido -porque está ofreciendo un testimonio- insta a que obremos de un modo en que no hagamos a los otros lo que no queremos que nos hagan a nosotros: como no queremos que nos ocupen, es "justo" (sic) y "lógico" (sic) que no ocupemos el espacio que no nos corresponde. Bien vista, esta exhortación pretende operar como punto de partida para el resto de la "discusión” en el sentido de que baliza desde la sanidad moral y mental las características que debería poseer todo aquel que quiera hablar seriamente del tema:

PV: ¿Es de muy mala persona decir que hay que marcar una prioridad para el argentino, o no? ¿Qué un argentino vaya al Hospital Rivadavia y tenga todos los turnos tomados?

En un momento (no se ve muy bien) parece que uno de los referentes invitados quiere hablar y hace una seña. El conductor le da la palabra. El referente la toma. Y de inmediato el panelista del imperativo categórico lo advierte en términos morales y cognitivos, casi tratándolo de mentiroso. El metamensaje acaso- sería el siguiente: "tú, enunciatario de mi enunciación, si vas a hablar, hazlo así, como yo digo... o no hables”. Justamente, en esa “discusión” no cabe otra subjetividad legítima que la que imagina el panelista portador de la ideología media. Veamos:

SDM: A ver, un minuto. Sí. Buenas noches.

(el referente) VDG: Buenas noches.

PV: Dígalo de verdad, eh? No haciéndose así todos los emotivos... porque después por atrás, la mayoría por atrás, sacando la palabra "resaca" sostienen que hay un desorden inmigratorio brutal en Argentina. Pero después en los medios todos se emocionan y después vienen a la Argentina y hay un destrato porque ni siquiera muchos están documentados, a muchos no los tienen en blanco, como dice Liliana para hacer trabajos que no quiere hacer ningún argentino.

\section{VDG: Estoy considerado como que estoy tergiversando.}

Dijimos que el enunciador imagina un hablante ideal sobre migración reciente en Argentina, una única figura apta para hacerlo. El resto de los hablantes, es decir, aquellos que no se reconocen en los "presupuestos" fuertes (Ducrot, 1994) de su ideario no son reconocidos como interlocutores, ya que -como mínimo- se los sospecha afectados por taras perceptivas de distinta procedencia. Vista en perspectiva, la brusca interrupción 
del panelista al referente puede etiquetarse como un argumento ad hominem. Se denomina así a un tipo de falacia que consiste en presuponer la falsedad de una afirmación tomando en cuenta no su información (que puede ser verdadera o falsa) sino al emisor de ésta. Quien argumenta de esta manera intenta desacreditar a la persona que defiende una postura señalándole a su persona (y no a sus saberes) la portación de una característica o creencia impopular que invalida definitivamente todo lo que pueda pensar y/o decir.

Pero entonces, si la subjetividad habilitada para el habla sobre la migración reciente en Argentina es una sola, y si la condición que se le hace respetar es la de reconocerse en los presupuestos fuertes de la lengua dominante, so pena de quedar excluida de los intercambios lingüísticos: ¿cabe decir que, hoy, en Argentina, se "discute" sobre el tema migratorio? Creemos que no.

Marcelo Dascal, filósofo y lingüista interesado en elaborar una reflexión que anude a la filosofía del lenguaje con la pragmática lingüística y la ciencia cognitiva, elaboró una interesante tipología de intercambios polémicos con que la que cerraremos este apartado.

Por intercambios polémicos entiende situaciones de habla interactivas en las cuales los puntos de vista de unos participantes son inseparables de los puntos de vista de los otros participantes. Cada punto es la movida siguiente de una movida que incitó -veremos que con medios distintos- a adoptar un cierta perspectiva. Así, más que de puntos de vista a secas debiera hablarse de los "estados" de los puntos de vista que, a través de la interacción, se remodelan más, o menos, o nada. Adviértase, aquí también, la perspectiva diacrónica necesaria para realizar el análisis.

Para el autor existen, a modo de tipos ideales, tres tipos de intercambios polémicos: la discusión”, la disputa y la controversia. Respecto de su estructura, una discusión “es un intercambio polémico dentro del cual, en la medida en que se desarrolla, los contendientes tienden a darse cuenta de que la raíz del problema que abordan se encuentra en un error.” (Dascal, 2007, p. 77). Respecto de su finalidad, dado que los interlocutores están dispuestos a admitir que existe una equivocación (no importa de quien sea), las discusiones llevan tendencialmente a la corrección de los errores y al establecimiento ex post de una "verdad” o a una mejor visualización del objeto de la polémica. Cierto aire de incertidumbre, en algún momento de los intercambios, forma parte de toda discusión.

La disputa es un intercambio polémico que se sitúa en las antípodas: como las discusiones también tienen un objeto de desacuerdo bien definido, pero en este caso los contendientes no aceptan en ningún momento definir el desacuerdo como fundado en el error [de alguno de ellos]. [Tampoco] existen procedimientos mutuamente aceptados para decidir la disputa; en otras palabras, una disputa no tiene solución, a lo sumo puede disolverse o ser disuelta. (Dascal, 2007, p. 78). En consecuencia, ningún momento de incertidumbre que lleve a la interacción cooperativa forma parte de una disputa, en las cuales las posiciones fundantes del desacuerdo no son pasibles de revisión alguna.

Las controversias ocupan un lugar intermedio. Dice Dascal:

no se reducen a conflictos sin solución. Los contendientes acumulan argumentos que creen que incrementan el peso de sus posiciones vis-á-vis las objeciones del adversario; intentan de este modo inclinar, si no la decisión sobre la materia en cuestión, al menos el "balance de razones" en su favor. [A diferencia de las discusiones y de las disputas] las controversias no llegan a una solución ni son disueltas. (Dascal, 2007, 78); antes que nada llevan al reconocimiento de la complejidad de una situación.

Así, las discusiones buscan soluciones mediante "verdades" establecidas ex post, las disputas el triunfo de una postura dentro de una competencia de posturas, y las controversias la persuasión por medio de un estado deliberativo. Para Dascal, siempre dentro de la tipología ideal, quienes se ponen a discutir presentan 
demostraciones, quienes se suman a una controversia presentan argumentos y quienes están en disputa suelen servirse de estratagemas, vista la necesidad del triunfo. Escribió: una estratagema es un movimiento que pretende causar una determinada (re)acción en una audiencia relevante, al inducirla a creer que una proposición es verdadera (...). La causación involucrada no requiere ser explícita y reconocible por la audiencia, siempre que logre el efecto pretendido, a saber, permitir al usuario "triunfar" (al menos momentáneamente) ante los ojos de una audiencia. El tipo particular de "fuerza" de este movimiento reside no en obligar al destinatario [a adoptar otra postura] (...) sino más bien en dejarlo "sin habla”, i.e., incapaz de reaccionar con un contra-movimiento satisfactorio. (Dascal, 2007, p. 83).

Fenómeno de notoria transversalidad, que no se agota, ni mucho menos, observando los programas que hemos analizado aquí, los discursos sobre la migración reciente en Argentina parecieran desplegarse mayormente dentro de disputas que, al menos hasta el momento, hacen imposible las discusiones y las controversias. Pareciera existir -extendida- una oscura estratagema, disfrazada de argumento: quienes son "políticamente correctos" (sic) con el tema migratorio, es decir, aquellos enunciadores que se entregan a largas cadenas de razonamientos para pensarlo en toda su complejidad, no son "sinceros" (sic) ni "marcan prioridad para un argentino” (sic). Por lo tanto, más vale que queden excluidos de las conversaciones concernientes a la proclamada refundación de la república.

\section{Cierre}

Inspirados en la noción de formación discursiva de Michel Foucault, hemos realizado una aproximación a la massmediatización de la migración reciente en Argentina aplicando el método del análisis sociológicolingüístico del discurso.

Por consiguiente, no nos animó ningún interés cognoscitivo particularmente lingüístico; al contrario, quisimos poner de relieve que la movilización de recursos lingüísticos particulares por parte de los enunciadores nos sirven de instrumento para comprender la idea de sociedad que subyace en sus referencias a este fenómeno. Tampoco nos animó el armado de ningún cotejo entre discurso y realidad; lejos de ello, quisimos hacer visibles las reglas o las rejillas de especificación (Foucault, 2008) a través de las cuales la misma formación discursiva hacer ver y hace hablar de la migración, dotándose así de su propio objeto. Mantuvimos en todo momento una perspectiva diacrónica que consideró que hay interacción y producción de subjetividades discursivas tanto en una (1) emisión televisiva como durante los aproximadamente veinte (20) días que duró este primer ciclo de discursos massmediáticos adversos a la migración.

Nuestro hallazgo principal reside -precisamente- en las subjetividades que construyen las interacciones discursivas, en particular, la de los enunciatarios. Nos encontramos en todo momento con una fuerte condición, autoritariamente restrictiva y abdicante, que la formación impone a todo quien quiera hablar sobre migración: abandonar el pensamiento "políticamente correcto" (sic), expresión que, en uso, significa pensamiento "progresista” o "garantista”. Si el enunciatario no cumple con la condición, su habla no será válida.

Quien recorra la agenda política -real e imaginada- de Argentina a partir de diciembre de 2015 y su recreación por los medios de comunicación, no tardará mucho en encontrar los ecos de esta condición para el habla de otros temas urticantes. $\mathrm{Y}$ es que podría proponerse una relación de proporciones entre la entronización de esta subjetividad hablante y la misión refundacional de la república que reclama para sí la actual alianza de gobierno. 


\section{Notas}

1 https://www.youtube.com/watch?v=IayBQ2qaUs4\&t=4205s (04/01/17)

$\underline{2}$ https://www.youtube.com/watch?v=tM3ykFIAXpc (04/01/17)

\section{$\underline{3}$ https://www.youtube.com/watch?v=HvQvRxw2jQQ\&t=3232s}

4 El análisis sociológico-lingüístico del discurso propuesto por Irene Vasilachis de Gialdino posee parentescos con la lingüística crítica” y, en especial, el análisis crítico del discurso, cultivado por autores como Norman Fairclough, Teun Van Dijk, Ruth Wodak, Luisa Martín Rojo y Lupicinio Iñíguez Rueda. Estos abordajes tomaron distancia de otras formas de investigación como el análisis del discurso, la lingüística textual y la sociolingüística, señalando que en estas aproximaciones el uso de la noción de contexto era escasa y/o ingenua. Para Wodak: "el análisis crítico del discurso estudia el discurso como práctica social y considera que el uso del contexto del lenguaje es crucial. Además, el análisis crítico del discurso se interesa de modo particular por la relación entre el lenguaje y el poder. (...). Tiene en cuenta, de modo muy concreto, los discursos institucionales, políticos, de género y mediáticos (en el más amplio sentido) que dan testimonio de la existencia de unas más o menos abiertas relaciones de lucha y conflicto. (...). Se propone investigar de forma crítica la desigualdad social tal como viene expresada, señalada, constituida, legitimada, etcétera, por los usos del lenguaje.” (Wodak, 2003, pp. 18-19).

$\underline{5}$ Referencias hasta el final de la parte 2. J. L.: Jorge Lanata. M. M.: Maximiliano Montenegro. R.M.: Romina Manguel. E. T.: Ernesto Tenembaum.

$\underline{6}$ Referencias hasta el final de la parte 3. M. A. P.: Miguel Ángel Pichetto.

$\underline{7}$ Referencias hasta el final de la parte 4. S. D. M.: Santiago del Moro. P. V.: Pablo Vilouta. P. R.: Paulino Rodrigues. R. G. L.: Ricardo Gil Lavedra. D. B.: Debora Plager. A. L.: Antonio Lage. V. D. G.: Víctor de Genaro.

\section{Bibliografía}

Charaudeau, P. y Maingueneau, D. (2005). Diccionario de análisis del discurso. Buenos Aires: Amorrortu.

Dascal, M. (2000). Tipos de polémicas y tipos de movimientos polémicos. En MARAFIOTTI, R. (Ed.), Parlamentos. Teoría de la argumentación y el debate parlamentario. Buenos Aires: Biblos.

Ducrot, O. (1994). El decir y lo dicho. Buenos Aires: Edicial.

Escandell Vidal, M. V. (2003). Introducción a la pragmática. Barcelona: Ariel.

Foucault, M. (2008). Arqueología del saber. Buenos Aires: Siglo XXI.

Garfinkel, H. (2006). ¿Qué es la etnometodología? Estudios sobre las bases rutinarias de la vida cotidiana [si es un artículo o capítulo debe tener una entrada aparte]. En Estudios en etnometodología. Barcelona: Anthropos.

Goffman, E. (1970). Sobre el trabajo de la cara La naturaleza de la deferencia y el proceder [si es un artículo o capítulo debe tener una entrada aparte]. En Ritual de la interacción. Buenos Aires: Tiempo Contemporáneo.

Goffman, E. (1974). La presentación de la persona en la vida cotidiana. Buenos Aires: Amorrortu. 
Goffman, E.(2006). FrameAnalysis. Los marcos de la experiencia. Madrid: Centro de Investigaciones Sociológicas.

Gusfield, J. R. (2014). Retórica y ciencia. La creación del orden cognitivo. En La cultura de los problemas públicos. El mito del conductor alcoholizado versus la sociedad inocente. Buenos Aires: Siglo XXI.

Maingueneau, D. (2009). Análisis de textos de comunicación. Buenos Aires: Nueva Visión.

Marafiotti, R. (Ed.). (2007). Parlamentos. Teoría de la argumentación y el debate parlamentario. Buenos Aires: Biblos.

Martín Rojo, L. y Van Dijk, T. (1998). “Había un problema y se ha resuelto”. Legitimación de la expulsión de inmigrantes "ilegales” en el discurso parlamentario español. En Martín Rojo, L. y R. Whittaker (Eds.), Poder-Decir, o el poder de los discursos. Madrid: Arrecife.

Mc Combs, M. (1994). The future agenda for agenda-setting research.Journal of Mass Communication Studies, 45, 171-181.

Meccia, E. (2006). La cuestión gay. Un enfoque sociológico. Buenos Aires: Gran Aldea Editores.

Meccia, E. (2015). Imaginación jurídica y experiencias trans. Una aplicación del método de análisis social del discurso. En BARRANCOS, D., GUY, D. y VALOBRA, A. (Eds.), Moralidades y comportamientos sexuales, Argentina, 1880-2011. Buenos Aires: Biblos.

Narvaja de Arnoux, E. (2008). El discurso latinoamericanista de Hugo Chávez. Buenos Aires: Biblos.

Snow, D. A., Burke Rochford, Jr, E., Worden, S. K. y Benford, R. D. (1986). Frame Alignment Processes, Micromobilization, and Movement Participation. American Sociological Review, 51(4), 464-481.

Thompson, K. (2014). Pánicos morales. Bernal: Universidad Nacional de Quilmes.

Van Dijk, T. (2003). Racismo y discurso de las elites. Barcelona: Gedisa.

Van Dijk, T. (2012). Discurso y contexto. Barcelona: Gedisa.

Vasilachis de Gialdino, I. (1997). La construcción de representaciones sociales: el discurso político y la prensa escrita. Un análisis sociológico, jurídico y lingüístico. Barcelona: Gedisa.

Vasilachis de Gialdino, I. (2007). Condiciones de trabajo y representaciones sociales. El discurso político, el discurso judicial y la prensa escrita a la luz del análisis sociológico-lingüístico del discurso. Discurso y Sociedad, 1(1).

Vasilachis de Gialdino, I. (2013). Análisis lingüístico e investigación cualitativa. En Discurso científico, político, jurídico y de resistencia. Análisis lingüístico e investigación cualitativa. Buenos Aires: Gedisa.

Vasilachis de Gialdino, I. (2016). La construcción discursiva de la identidad y el modelo de sociedad en el discurso político de Mauricio Macri. Discurso \& Sociedad, 10(3), 466-490.

Wodak, R. (2003). De qué trata el análisis crítico del discurso (ACD). Resumen de su historia, sus conceptos fundamentales y sus desarrollos”. Barcelona.

Wodak, R. y Meyer, M., Métodos de análisis crítico del discurso. Barcelona. 